\title{
UMA REFORMA NECESSÁRIA
}

\author{
Carlos Benedito Martins*
}

\begin{abstract}
RESUMO: Tendo como referência determinadas transformações que têm ocorrido nos contextos do ensino superior no cenário internacional e no país, nas últimas décadas, o artigo analisa o projeto de reforma delineado pelo governo federal. Assinala determinados aspectos positivos do projeto de reforma e ao mesmo tempo salienta que ele representa uma oportunidade para estabelecer um novo pacto acadêmico entre os diversos atores que atuam no sistema, tendo como parâmetros o compromisso com a qualidade acadêmica e a recuperação da dimensão pública do ensino superior brasileiro.

Palavras-chave: Reforma do ensino superior. Democratização das oportunidades educacionais. Expansão do sistema. Privatização do ensino superior. Universidades públicas.
\end{abstract}

\section{A NECESSARY REFORM}

ABSTRACT: Based on certain transformations that have taken place, these last years, in both the international and Brazilian contexts of higher education, this paper analyzes the reform project presented by the federal government. It points out some of its positive aspects and, at the same time, stresses that it represents an opportunity to establish a new academic pact, among the diverse actors involved in the system, which could be grounded on a commitment towards academic quality and the rescue of the public dimension of Brazilian higher education.

Key words: Higher education reform. Democratization of the educational chances. Expansion of the system. Privatization of the higher education. Public universities.

* Doutor em Sociologia pela Universidade de Paris V e professor do Departamento de Sociologia da Universidade de Brasília (UnB).E-mail: cm2462@columbia.edu

Educ. Soc., Campinas, vol. 27, n. 96 - Especial, p. 1001-1020, out. 2006

Disponível em <http://www.cedes.unicamp.br> 
ntes de tecer comentários específicos a respeito de determinados aspectos do projeto da reforma do ensino superior brasileiro, gostaria de fazer breves considerações sobre certas tendências internacionais do ensino superior contemporâneo, com o propósito de alargar o escopo de compreensão de algumas medidas propostas pelo referido projeto.

A análise dos sistemas de ensino superior, em diferentes contextos societários, tende a indicar que eles têm ocupado uma posição estratégica na modernidade em sua fase atual, em função das complexas relaçōes que mantêm com o processo de desenvolvimento econômico, com a valorização do conhecimento técnico e científico, com as crescentes exigências sócio-políticas do processo de democratização e de igualdade de oportunidades e com a modernização de suas respectivas sociedades. O Estado, em diversos países centrais, tem desempenhado um papel destacado na formulação e implementação de políticas públicas na área do ensino superior, visando o aprimoramento de sua qualidade acadêmica e de sua pertinência social (Guadilla, 2002; Duderstadt, 2004; Weber, 2004).

Uma das tendências centrais do ensino superior contemporâneo, em escala internacional, diz respeito à ampliação do seu acesso, fenômeno que se iniciou a partir da segunda metade do século XX. Um conjunto de fatores tem contribuído para esse processo, tais como a valorização do conhecimento técnico e científico como um dos ingredientes centrais das sociedades modernas, pressões por direitos sociais, aspirações de mobilidade social por meio do sistema educacional, por parte dos estudantes e de suas famílias, necessidade da aquisição de competências técnicas para enfrentar um mercado de trabalho cada vez mais instável e seletivo, transformações no conteúdo das profissões, trazendo de volta para os bancos escolares uma população adulta e já integrada em atividades profissionais etc. (Schwartzman, 1997; Natrajan, 2003; Nuna, 2003).

Inicialmente voltado para uma restrita clientela dotada de capital econômico e cultural, o ensino superior passou a incorporar gradativamente novos grupos sociais, que até então estavam às suas margens, em função de pressões sociais para sua democratização. As matrículas no ensino superior praticamente duplicaram nos quatro cantos do mundo: em 1975, somavam pouco mais de 40 milhōes de estu- 
dantes e, em 1995, superaram a cifra de 80 milhões. Entre 1980 a 1995, na América do Norte, passou-se de 13 para 16 milhões de estudantes; na Europa, de 7 para 12 milhôes de estudantes e na América Latina/Caribe, registrou uma expansão de 5 para 8 milhões de alunos matriculados em nível superior. Os dados disponíveis indicam que, no período de 1980 a 1995 , praticamente todos os países experimentaram taxas elevadas de crescimento, fenômeno esse que tem se intensificado nos dias atuais. Simultaneamente com o processo de expansão, vários países têm criado sistemas de avaliação para aferir e aprimorar a qualidade de ensino oferecido para suas populaçōes (Barrow, 1990; Barber, 1992; Bourdieu, 1998; UnEsCo, 1999; Banco Mundial, 2000; Guadilla, 2004; Trumbic, 2005).

Paralelamente ao processo de ampliação de acesso ao ensino superior, tem ocorrido uma retração do financiamento público que, de modo geral, não tem acompanhado o ritmo da demanda, que tem assumido feiçōes específicas em cada sociedade concreta. Algumas análises têm chamado a atenção para a emergência de um "capitalismo acadêmico", no interior do qual passou a ocorrer um crescente engajamento das instituições de educação superior com empresas privadas, como uma estratégia de captação de recursos, para compensar a tendência de retração do aparelho estatal no financiamento de universidades sob a sua responsabilidade. Por outro lado, deve-se assinalar que várias agências multilaterais, que atuam no plano internacional, têm delineado e promovido um modelo de ensino superior calcado num afastamento do Estado com relação ao financiamento público de suas instituições, incentivando-as a gerar seus próprios recursos por meio de cobrança de anuidades e/ou de parcerias com empresas, bem como impulsionando uma maior abertura para a participação de instituições privadas no conjunto do sistema. $\mathrm{Na}$ mesma esteira, recomendam também a transferência de recursos financeiros do ensino superior para a educação básica, apoiando-se na premissa de que o ensino público subsidia uma camada média e/ou grupos privilegiados que possuem condiçôes para arcar com os custos de seus estudos (ARESR, 1997; Bourdieu, 1998 e 2002; Slaughter, 2004 e 2006; Torres, 2006; Boron, 2006).

A tendência de diminuição da participação do setor público tem ocorrido simultaneamente com a crescente presença do setor privado na oferta de serviços educacionais, em plano internacional, realizada por 
uma multiplicidade de instituições, algumas com propósitos filantrópicos e outras operando como empresas educacionais.

Tomando como referência a América Latina e o Caribe, os dados indicam que nas últimas décadas houve um vertiginoso crescimento das matrículas do setor privado. Em 1995, sua presença era dominante em países como República Dominicana (72\%,), El Salvador (69\%), Chile (53\%), Colômbia (64\%) e Brasil (65\%). Dados mais recentes tendem a indicar uma elevação desses patamares, como mostra o caso brasileiro no qual, atualmente, a iniciativa privada responde aproximadamente por $80 \%$ das instituições de ensino superior (Guadilla, 2004; Ruch, 2001; Trindade, 2002; Petroukovitch, 1999; Altbach, 1998; ARESR, 1997; INEP, 2003; Rusch, 2001).

Ao longo de sua história, o ensino superior em diversos países esteve estruturado basicamente na existência de universidades, de tal forma que esses dois termos designavam fenômenos praticamente equivalentes. Até 1300, existiam no mundo ocidental não mais que 15 universidades. Em 1500, esse número aumentou para 50, saltando para 95 unidades em 1700. Gradativamente, foi ocorrendo uma expansão do número de universidades de tal forma que, por volta de 1970, podia-se contar aproximadamente 920 delas no Ocidente, sendo que a partir desse período intensificou-se o processo de surgimento de novas universidades em vários países (Hofstadter, 1971; Bayen, 1973; Cobban, 1975; Haskins, 1977; Lucas, 1994).

Paralelamente ao crescimento do número de universidades, o ensino superior tem experimentado um intenso processo de diversificação institucional, por meio do surgimento de novos e variados formatos organizacionais/institucionais, tais como Comunity Colleges nos EUA, Fachhochschule na Alemanha, Institut Universitaires de Recherche na França e Polytechnics na Inglaterra, que passaram a coexistir com o modelo universitário. Esse processo possui relação com a intensificação da divisão e especialização do trabalho que tem marcado as sociedades modernas. Mantém também uma conexão com a emergência de uma multiplicidade de expectativas de formação acadêmico-profissional que as novas gerações possuem com relação ao ensino superior, assim como com a disposição dos administradores acadêmicos, sejam públicos ou privados, de conectar essa diversidade de expectativas profissionais com nichos mais específicos do mercado de trabalho. $\mathrm{Na}$ medida em que a 
universidade, gradativamente, deixou de se constituir o modelo unívoco para a estruturação das atividades acadêmicas, iniciou-se um derretimento da equivalência entre ensino superior e universidade, que prevaleceu durante séculos. Nesse contexto, mais diversificado institucionalmente, determinadas universidades, em diversas sociedades concretas, continuaram a ocupar um papel destacado nas atividades de ensino e pesquisa e na condução da vida cultural de seus países (Duderstadt, 2000).

$\mathrm{O}$ ensino superior tem experimentado também uma ampliação de suas funções e raio de atuação. Além de desempenhar seus clássicos papéis de ensino e pesquisa, tem assumido em diversos países outras funçôes, tais como contribuir para o fortalecimento da competitividade da economia, fornecer treinamento especializado para atender as necessidades do mercado de trabalho, atender demandas de empresas privadas, formar quadros para as burocracias públicas, prestar serviços para o aparelho estatal etc. Em função dessas relações que o ensino superior passou a estabelecer com o ambiente externo, iniciou-se um gradativo processo de revisão de sua própria identidade institucional, até então calcada num modelo universitário humboltiano, que tendia a preservar sua autonomia intelectual diante das demandas do mundo externo. Se, por um lado, essa ampliação das funções do ensino superior lhe conferiu uma expressiva visibilidade no interior das instituiçōes culturais da modernidade, em sua fase atual, por outro, ao mesmo tempo tem contribuído para torná-lo mais vulnerável quanto à preservação de sua relativa autonomia institucional diante das múltiplas demandas advindas do campo econômico e político, e dos atores que atuam nesses espaços sociais (Shapiro, 2005; Bok, 2003; Readings, 1996; OCDE, 1987; Kerr, 1982; Souza Santos, 1985 e 2005).

Diante desse quadro delineado grosso modo e de seus problemas específicos, o ensino superior brasileiro encontra-se diante de vários desafios que têm de ser enfrentados de forma decisiva.O sistema necessita de uma urgente expansão de suas matrículas, associada a políticas que promovam a democratização de seu acesso, propiciando a inclusão de grupos sociais que historicamente têm permanecido à sua margem. Sem dúvida, necessita de um novo pacto acadêmico que possibilite recuperar a dimensão estratégica da educação no processo de modernização e democratização do país, bem como recuperar a sua dimensão enquanto um bem público. Por outro lado, torna-se fundamental rever a lógica que tem comandado o seu funcionamento ao longo das últimas 
quatro décadas, em larga medida, ancorada na intensificação do processo de privatização e na corrosão de parte significativa das universidades públicas. Nesse sentido, é fundamental resgatar o papel do Estado como um ator central nos processos de formulação de políticas públicas para o sistema e na avaliação da qualidade acadêmica das instituiçôes. Paralelamente, o Estado precisa se posicionar de forma clara no processo de recuperação das universidades públicas, que precisam ser potencializadas e apoiadas de forma clara e decidida pelo governo federal. O ensino superior deve ampliar sua interação com diferentes grupos sociais, com o mundo do trabalho, com o setor produtivo, preservando ao mesmo tempo uma atitude pluralista diante das demandas extra-acadêmicas. Inúmeros outros problemas poderiam ser acrescentados, indicando a urgente tarefa de se repensar a totalidade do sistema de ensino superior e de suas relações com a sociedade brasileira, sem perder de vista os desafios advindos de um contexto internacional cada vez mais interdependente.

A última reforma do ensino superior brasileiro ocorreu em 1968. Teve como antecedente um significativo movimento de estudantes e de professores que, desde o início da década de 1960, vinham se mobilizando intensamente para imprimir novos rumos na incipiente vida acadêmica nacional. Na metade da década de 1960 , o país contava com aproximadamente 150 mil estudantes distribuídos em torno de duas centenas de instituições de pequeno porte, voltadas fundamentalmente para a atividade de ensino e reprodução de quadros da elite brasileira, sendo que a maioria dos estabelecimentos pertencia ao sistema público. O desfecho da reforma universitária ocorreu em pleno regime autoritário e sua elaboração foi confiada a um restrito grupo de trabalho designado pelo governo militar. O decreto n. 62.937/68, que instituiu o GT da Reforma Universitária, deu um prazo de 30 dias aos seus integrantes para apresentação do projeto final. Consoante com o espírito dominante na época, a sua redação não contou com nenhuma discussão com a comunidade acadêmica, que se encontrava sob forte vigilância por parte dos órgãos de segurança do governo.

Os princípios que a orientaram, voltados em larga medida para as instituiçōes universitárias - consideradas pelo GT da Reforma como "o tipo natural de estrutura para o ensino superior" -, foram a expansão com contenção de despesas das universidades públicas, a eficiência operacional e a racionalização das atividades acadêmicas (unificação dos 
vestibulares, criação dos departamentos, sistema de créditos etc.). Apesar do seu viés autoritário, algumas de suas medidas, como implantação da carreira docente e da pós-graduação, modernizaram uma parte significativa do sistema de ensino superior, de modo destacado em determinadas universidades públicas, onde se tendeu a concentrar o essencial da atividade de pesquisa realizada no país. Houve um sensível avanço na profissionalização da carreira acadêmica e na institucionalização da pósgraduação nacional, que atualmente é considerada pelos especialistas como a melhor da América Latina. Ao mesmo tempo, na medida em que não conseguiu expandir a oferta do ensino público, a reforma abriu espaço para a expansão do setor privado laico, que teve uma acolhida bastante favorável pelo antigo Conselho Federal de Educação ( $\mathrm{CFE}$ ).

A partir da reforma universitária de 1968, formou-se gradativamente um complexo campo acadêmico, no interior do qual tem ocorrido uma diversificação de formatos institucionais e de vocações acadêmicas por parte das instituições que o integram. Ao contrário do modelo de organização do ensino superior delineado pela Reforma de 1968 - calcado prioritariamente no modelo universitário -, as universidades representam tão somente $8,8 \%$ das instituições do atual sistema. O restante é respondido pela participação de $75,5 \%$ das faculdades, escolas e institutos, $6,4 \%$ das faculdades integradas, sendo que os centros universitários têm uma presença de $4,3 \%$ e os centros de educação tecnológica $5 \%$ no conjunto do sistema. Esse universo de instituições apresenta um desempenho acadêmico bastante heterogêneo e assimétrico, em termos de qualidade de suas atividades, não apenas entre as instituiçōes públicas e privadas, mas também no interior de cada um desses dois segmentos que, a rigor, não constituem blocos homogêneos do ponto de vista acadêmico. Segundo dados do Censo da Educação Superior, em 2003 existiam 3,8 milhões de alunos matriculados nos cursos de graduação no país, que se encontravam inseridos em 1.859 instituições. Ao contrário da pós-graduação, que desde o início de sua implantação foi planejada e acoplada a um eficiente sistema de avaliação, em larga medida, o ensino de graduação expandiu-se de forma desorganizada, ao sabor da demanda do mercado, experimentando tardiamente o processo de avaliação, que foi introduzido somente na metade da década de 1990. No bojo desse processo de mudanças, houve a incorporação de um público mais diferenciado socialmente, um aumento significativo de estudantes do gênero feminino, a absorção de 
uma expressiva parcela de estudantes integrados ao mercado de trabalho, a interiorização e regionalização da oferta do ensino superior, a institucionalização da profissão acadêmica em diversas instituições, bem como a formação de um vigoroso sistema nacional de pós-graduação, que tem contribuído para o desenvolvimento da pesquisa e da tecnologia no país.

Apesar do crescimento da graduação, deve-se registrar que pouco mais de $10 \%$ de jovens, na faixa etária entre 18 e 24 anos, encontram-se cursando o ensino superior no país - um dos mais baixos do continente -, o que evidencia a necessidade de enfrentar com urgência a expansão do sistema e simultaneamente a universalização do ensino médio, requisito fundamental para a democratização do ensino superior. Grosso modo, assistiu-se, durante as últimas três décadas, a um contínuo declínio da participação da rede pública na participação do sistema em favor das instituiçôes privadas, tanto em termos de instituiçōes quanto em termos de matrículas. Em 1965, o sistema público respondia por 57\% das instituiçôes e 56\% das matrículas; já em 2003, esse percentual havia decrescido para $11 \%$ e $29 \%$, respectivamente. Nas últimas três décadas gerouse também um espesso cipoal de leis, decretos-leis, resoluções de conselhos, portarias ministeriais e, mais recentemente, medidas provisórias voltados para o funcionamento do ensino superior.

Em função desse quadro, a proposta de reforma é oportuna, na medida em que o ensino superior brasileiro necessita de uma profunda revisão do caminho que trilhou nas últimas décadas, capaz de estabelecer diretrizes gerais, que propiciem organicidade e maior qualidade acadêmica à totalidade do sistema, e definir suas perspectivas futuras. Ao contrário da elaboração da Reforma de 1968, tem ocorrido uma ampla participação da comunidade acadêmico-científica durante o processo de construção do atual projeto de reforma. $\mathrm{O}$ atual projeto de lei, que serve como referência para a presente discussão, constitui um avanço em relação as suas versôes anteriores, na medida em que eliminou uma série de antinomias diante dos marcos legais que regulam o ensino superior. A nova versão, ao contrário das anteriores - que possuíam um teor extremamente detalhista, consubstanciado em mais de 100 artigos -, ganhou uma tonalidade de orientações gerais, expressa em pouco mais de 50 artigos. Por outro lado, a nova versão logrou um maior equilíbrio entre normas gerais para o funcionamento do sistema e o respeito à diversidade acadêmico-institucional, construída por cada instituição 
para adotar suas próprias diretrizes de ensino, pesquisa e extensão, em função de sua trajetória institucional e sua inserção regional.

$\mathrm{O}$ atual projeto de reforma do ensino superior encontra-se estruturado em três eixos fundamentais: resgatar e consolidar a responsabilidade social da educação superior, construir um marco regulatório para o funcionamento da totalidade do sistema e assegurar a autonomia universitária prevista no dispositivo 207 da Constituição Federal. Um dos vetores fundamentais que permeia a elaboração do projeto baseia-se no pressuposto de que o funcionamento do ensino superior não deve ser comandado prioritariamente pelo livre jogo do processo de concorrência existente no interior do mercado educacional. Ao contrário disso, o projeto procura recuperar o papel do Estado como um outro ator central, ao qual é atribuído um papel primordial na configuração e condução do sistema. De maneira acertada, o projeto se contrapõe às determinadas orientaçōes de diversas agências multilaterais, que têm recomendado uma desregulamentação do funcionamento do sistema, repondo a responsabilidade do Estado no estabelecimento de marcos regulatórios e no financiamento das instituiçôes federais.

Ao contrário da Reforma de 1968, cuja orientação básica era interligar o ensino superior com a produtividade do sistema econômico, percebe-se que um dos alvos fundamentais do anteprojeto, explicitado na seção em que trata das disposiçôes gerais do ensino superior, é enfatizar o sentido da educação como um bem público, atribuindo-lhe uma função social. $\mathrm{O}$ artigo 4 do projeto de lei explicita que a função social do ensino superior será atendida por meio de requisitos tais como: democratização do acesso, formação acadêmica e profissional conforme padrões de qualidade a serem aferidos por procedimentos de avaliação institucional, articulação do ensino superior com a educação básica, promoção da diversidade cultural. Na mesma perspectiva, o artigo em tela estabelece que as instituições devem manter uma interação permanente com a sociedade, por meio de sua inserção regional ou nacional, bem como uma interação com o mundo acadêmico internacional, por meio de intercâmbio de docentes e estudantes e da realização de projetos de pesquisa com instituições estrangeiras. $\mathrm{O}$ mesmo artigo estipula que as atividades acadêmicas das instituiçôes devem ser geridas de forma democrática, através de organização colegiada, assegurando a participação de diversos segmentos que a integram. Acertadamente, determina a valorização profissional dos docentes e do pessoal técnico e 
administrativo das instituiçóes, estimulando-as a propiciar condições de formação continuada de seus quadros profissionais.

O projeto em tela, no seu artigo 19, determina que as instituições deverão elaborar seus planos de desenvolvimento institucional, identificando sua vocação educacional e definindo os campos do saber de sua atuação. Estipula também a necessidade do estabelecimento de ensino de explicitar a relação entre o seu projeto pedagógico e as finalidades da educação delineadas pelo atual projeto, assim como a demonstração do compromisso social da instituição. As instituições devem contemplar também uma análise do cumprimento das metas estabelecidas no plano de desenvolvimento institucional anterior, sendo que suas ações e realizações serão analisadas de forma periódica pelas instâncias competentes. Essa iniciativa, que na verdade já vem sendo adotada, não deveria ser encarada pelas instituições como uma mera formalidade burocrática. Caso esse expediente seja utilizado como uma real oportunidade para os estabelecimentos explicitarem seus perfis institucionais, delinearem suas verdadeiras vocações acadêmicas e estabelecerem suas relações com os contextos regionais ou nacional, poderá representar um instrumento fundamental no processo de diversificação acadêmicoinstitucional do ensino superior no país.

Conforme foi assinalado, a Reforma de 1968 propunha a estrutura da universidade como modelo unívoco para o funcionamento do sistema. $\mathrm{O}$ atual projeto, de forma adequada, distancia-se dessa orientação, uma vez que, partindo do funcionamento atual do sistema, estabelece uma tipologia de instituiçôes (universidades, centros universitários, faculdades), fixando critérios e prerrogativas para cada uma dessas modalidades. Com isso, o projeto preserva a atual diversificação acadêmico-institucional existente no interior do sistema, mantendo uma sintonia com as transformações que vêm ocorrendo no plano internacional com relação a esse quesito. Além de se organizarem de maneira compatível com suas peculiaridades e vocações acadêmico-institucionais, o projeto assegura aos estabelecimentos a prerrogativa de fixar os conteúdos acadêmicos de seus cursos e programas, observando as diretrizes curriculares pertinentes.

Em termos de marco regulatório, o artigo 11 estabelece que as instituições de ensino superior deverão observar determinadas diretrizes, tais como: implementação de planos de carreira, capacitação e treinamento para docentes e pessoal técnico-administrativo, avaliação 
institucional interna e externa, organização colegiada, garantia de condiçōes dignas de trabalho aos docentes e pessoal técnico-administrativo. De forma acertada, estipula a proteção de liberdade acadêmica contra o exercício abusivo do poder interno ou externo à instituição. No sentido de propiciar maior transparência para o funcionamento das instituições, o artigo 25 estabelece a existência de uma ouvidoria, cujo titular eleito diretamente pelos segmentos da comunidade deverá ter estabilidade no exercício de seu mandato.

O projeto condiciona o credenciamento e sua renovação periódica dos estabelecimentos que integram o sistema federal de ensino (instituições mantidas pela União e instituições privadas) aos resultados obtidos pelo processo de avaliação, a ser conduzida pelo Sistema Nacional de Avaliação de Educação Superior (SINAES). Por meio desse expediente, o projeto de reforma procura acoplar a necessária expansão das matrículas com a manutenção de padrões de qualidade a serem averiguados pelo SINAES.

Ainda com relação aos marcos regulatórios, o artigo 12, acertadamente, eleva o padrão de exigência para as universidades, uma vez que, além de determinar a existência de estrutura pluridisciplinar e a indissociabilidade entre ensino, pesquisa e extensão, exige que elas devam contar com pelo menos um terço do corpo docente em regime integral e a metade de seus professores com titulação de mestre ou doutor, devendo também possuir no mínimo três cursos de mestrado e pelo menos um de doutorado. As universidades terão um prazo de seis anos para implantar seus cursos de mestrado e de oito anos para o de doutorado, a partir da publicação da lei. Essa medida e outras correlatas são importantes para recuperar determinadas características acadêmicas e o sentido intelectual que o mundo ocidental tem atribuído às universidades, entre as quais se destaca a produção de novos conhecimentos. Como se sabe, a partir da década de 1980, ocorreu uma expansão de instituições universitárias nos país, em larga medida impulsionada pelo setor privado, que, de modo geral, tem funcionado muito mais como uma aglutinação de cursos de graduação, voltados para o treinamento de profissões específicas, do que efetivos centros geradores de pesquisas científicas e tecnológicas. Digase, de passagem, que a emergência de universidades que se aproximam mais de uma aglutinação de escolas isoladas, corroendo o sentido acadêmico dessa modalidade de organização do ensino superior, existe também, lamentavelmente, no plano internacional (Altbach, 2001). 
Procurando assegurar a participação da sociedade civil no desenvolvimento institucional da universidade, o projeto prevê a criação de um conselho de desenvolvimento social para essas instituições, tanto públicas quanto privadas. Seria oportuno assinalar que a Reforma de 1968 já incentivava a presença da comunidade na administração das instituiçōes, ao lado de professores e estudante. A LDB, em seu artigo 56, estipula também que as instituições públicas obedecerão ao princípio da gestão democrática, devendo contar com a participação dos segmentos da comunidade institucional, local e regional em seus órgãos colegiados deliberativos. Em vários países, as universidades contam com a participação de membros externos em conselhos de sua gestão, como um instrumento de articulação com as sociedades que as permeiam (Rodhes, 2004; Crocheet, 2004).

O artigo 20, que cria esse Conselho de caráter consultivo, estabelece que ele tem a função de assegurar a participação da sociedade em assuntos relativos ao desenvolvimento institucional da universidade e as suas atividades de ensino, pesquisa e extensão. Além disso, o Conselho tem as atribuições de dar amplo conhecimento público das atividades acadêmicas da universidade, com vista à avaliação de sua efetividade como instituição, acompanhar a execução do plano de desenvolvimento institucional e indicar demandas da sociedade para a fixação das diretrizes e da política geral da universidade, bem como opinar sobre todos os assuntos que lhe forem atribuídos. Sua composição prevê a participação do reitor, que o preside, assim como a representação majoritária e plural de representantes da sociedade civil. Certamente, o incentivo a uma maior articulação da universidade com o seu contexto externo, por meio de uma participação plural de diversos grupos sociais, constitui uma iniciativa correta. No entanto, torna-se necessário manter uma atitude de vigilância, no sentido de não permitir que o funcionamento desse conselho possa representar um constrangimento à livre produção e disseminação do conhecimento e um obstáculo ao exercício da autonomia intelectual que deve presidir a realização do trabalho acadêmico.

Com relação à autonomia universitária, o artigo 14 estabelece que as universidades, tanto públicas quanto privadas, gozam da prerrogativa de definir seu projeto acadêmico-científico e de desenvolvimento institucional, assim como criar e extinguir cursos na sua sede e fixar número de vagas. Confere também às universidades a liberdade para elaborar suas normas próprias, escolher seus dirigentes e administrar seu 
pessoal docente, discente, técnico-administrativo e gerir seus recursos materiais. $\mathrm{O}$ mesmo artigo assegura a autonomia de gestão financeira e patrimonial para gerir recursos dessa natureza. Deve-se assinalar que a versão anterior contemplava de forma mais explicita a autonomia das universidades federais que, sem dúvida, constitui um desafio central a ser enfrentado no contexto da reforma do ensino superior. Apesar do caráter genérico em que foi abordada a autonomia das universidades federais, o atual projeto representa um passo adiante no processo de desatrelamento burocrático dessas universidades diante do MEC. Não se pode esquecer que, desde a edição do Estatuto das Universidades Brasileiras, em 1931, as entidades de ensino mantidas pela União têm sido tratadas como repartiçôes públicas, aprisionadas à sua centralização administrativa, obstaculizando a possibilidade destas estabelecerem uma política de administração de seu quadro pessoal, assim como gerirem seus recursos financeiros de forma mais adequada.

Nenhum país moderno se desenvolveu sem possuir um forte sistema de ensino superior público. Nesse sentido, percebe-se através do projeto um claro comprometimento da União com a manutenção e financiamento da rede pública federal. $\mathrm{O}$ ensino público no país tem de enfrentar o desafio do aumento do número de vagas nos cursos de graduação e de pós-graduação, como um imperativo do processo de democratização das chances educacionais, necessitando, portanto, de recursos financeiros adequados e estáveis. Como se sabe, as instituiçōes federais, nos últimos tempos, enfrentaram sérias dificuldades advindas da diminuição de seu financiamento, o que tem refletido na precarização do trabalho docente e na deterioração de suas condições de infraestrutura de trabalho. A esse propósito, deve-se assinalar que, somente em 2005, as instituições federais recuperaram o patamar de seu financiamento existente em 1995. Não se pode esquecer que existem setores na sociedade brasileira que defendem de forma explicita - e ao mesmo tempo equivocada - que o Estado deveria livrar-se do financiamento das universidades federais, que são vistas como um pesado fardo por esses setores. Ao contrário dessa perspectiva, devido à importância estratégica que as instituiçóes federais possuem no conjunto do país, cumpre reconhecer que elas precisam ser decididamente apoiadas pelo governo federal. Nessa perspectiva, o artigo 43 estipula que a União aplicará, durante o período de dez anos, nas instituições federais, nunca menos de $75 \%$ da receita constitucionalmente vinculada à manu- 
tenção e desenvolvimento do ensino. Prevê-se também a exclusão nesse cálculo das despesas realizadas com inativos e pensionistas dos estabelecimentos federais, sem prejuízo de seus direitos específicos, o que representa uma significativa desoneração do orçamento para as instituiçôes federais. De forma correta, o artigo 36 assegura a gratuidade do ensino nos estabelecimentos federais.

Essa garantia de um financiamento adequado e estável para as instituições federais vem acompanhada da atribuição de uma responsabilidade social na gestão dos recursos públicos. $\mathrm{O}$ artigo 43 estabelece um conjunto de critérios para a distribuição de recursos, tais como número de matrículas e de concluintes nos cursos de graduação e pós-graduação, oferta desses cursos em diferentes campos do saber, relação entre o número de alunos e o número de docentes, a produção institucionalizada de conhecimento cientifico, tecnológico, cultural e artístico, registro e comercialização de patentes, bem como os resultados obtidos pelas instituições no processo de avaliação comandado pelo SINAES. O projeto prevê, também, através do artigo 45, que as instituições federais deverão formular e implantar, por meio de seu plano de desenvolvimento institucional, medidas de democratização do acesso, inclusive programas de assistência estudantil, ação afirmativa e inclusão social. Esse mesmo artigo determina que elas deverão oferecer, pelo menos, um terço de seus cursos e matrículas de graduação no turno noturno, com exceção para cursos em turno integral.

Lamentavelmente, a universidade brasileira, ao longo das últimas quatro décadas, enquanto tendência, foi se fechando em suas respectivas áreas de conhecimento, ancoradas numa rígida estrutura departamental que tem demonstrado notória dificuldade tanto no estabelecimento de um diálogo acadêmico entre elas, quanto no desenvolvimento de um conhecimento mais interdisciplinar. Essa especialização, que vem corroendo o espírito universalista que deveria pautar a universidade, soma-se à opção profissional precoce que os estudantes são obrigados a fazer. Por outro lado, os cursos de ensino superior no país têm se comportado, em grande medida, como reféns das diversas profissōes que têm comandado a estruturação da organização acadêmica, por meio da existência de departamentos especializados, faculdades e institutos. Dessa forma, os cursos de graduação, na maioria das vezes, têm propiciado uma estreita formação acadêmica, calcada numa especialização profissional e fadada a tornar-se irrelevante nas sociedades contemporâ- 
neas, marcadas por constantes e profundas mudanças em suas diferentes esferas, nas quais estão cada vez mais presentes os princípios da incerteza e da ambivalência. Um dos desafios centrais do ensino superior brasileiro é repensar o tipo de formação acadêmica que vem sendo propiciada aos seus estudantes, procurando equilibrar a aquisição de conhecimentos numa determinada área profissional específica com uma formação intelectual mais generalista, de cunho humanístico, capacitando-os a analisar e situar-se diante do processo de mutaçōes das sociedades contemporâneas e de seus inerentes riscos, imprevistos e incertezas, que perpassam as esferas pessoais, sociais e profissionais. Esse debate, que vem ocorrendo em escala internacional, não foi devidamente contemplado pelo atual projeto. Ao mesmo tempo, não foi enfrentado com o vigor que se faz necessário às questôes da reestruturação da departamentalização/segmentação/especialização do conhecimento que tomou conta da universidade brasileira e o seu impacto empobrecedor na formação intelectual das novas gerações (Arnove, 1998; Jacoby, 1990 e 2001; Beck, 1999 e 2004; Bauman, 2001 e 2005; Ribeiro, 2003).

O projeto, de maneira geral, apresenta pontos positivos no processo de uma reforma do ensino superior. Mantém sintonia com determinadas tendências que estão ocorrendo no cenário internacional, tais como a democratização do acesso ao ensino superior, diversificação acadêmica e institucional dos centros de ensino, ampliação das funçóes do ensino superior, busca de uma maior pertinência social da atividade acadêmica etc. Procura também estabelecer um marco regulatório para as instituições, com vista à preservação de sua qualidade acadêmica. De forma adequada, distancia-se de certas sugestôes formuladas por organismos multilaterais, tais com a desregulamentação do ensino superior, transferência de fundos públicos da educação superior para outros níveis de ensino, diminuição da participação estatal no financiamento das universidades públicas etc. $\mathrm{O}$ projeto contém pontos relevantes na recuperação da dimensão estratégica da educação superior, no processo de modernização e democratização do país, da retomada de sua dimensão pública. Ao mesmo tempo, aponta para o fortalecimento do ensino público, apresenta avanços significativos quanto à recomposição da universidade federal, especialmente quanto ao seu financiamento. A discussão da tramitação do atual projeto de reforma deveria constituir uma oportunidade para o estabelecimento de um novo pacto acadêmico por parte dos diferentes atores e segmentos envolvidos no ensino su- 
Uma reforma necessária

perior brasileiro, orientado pelo compromisso de sua qualidade acadêmica e de sua pertinência social.

Recebido e aprovado em agosto de 2006.

Referências bibliográficas

ALTBACH, P. The rise of the pseudouniversities. International Higher Education, Boston, n. 25, 2001.

ASSOCIATION DE REFLEXION SUR L'ENSEIGMENT SUPERIEUR ET LA RECHERCHE (ARESR). Une université en péril. Paris: Raisons d'Agir, 1997.

ARNOVE, R. Emergent issues in education. New York: Sunny, 1998.

BAYEN, M. Histoires des universités. Paris: PUF, 1973.

BANCO MUNDIAL. The task force on higher education society: peril and promise. Washington, DC, 2000.

BARBER, C. An aristocracy of everyone: the politics of education and the future of America. New York: Ballantine, 1992.

BARROW, C. Universities and the capitalist State. Madison: University of Wisconsin, 1990.

BAUMAN, Z. Modernidade líquida. Rio de Janeiro: Zahar, 2001.

BAUMAN, Z. Identidade. Rio de Janeiro: Zahar, 2005.

BECK, U. O que é globalização?: equívocos do globalismo à globalização. São Paulo: Paz \& Terra, 1999.

BECK, U. The risk society: towards a new modernity. London: Sage, 2004.

BOK, D. University in the marketplace: the commercialization of the higher education. New Jersey: Princeton University, 2003.

BORON, A. Reforming the reforms: transformation and crisis in Latin America. In: Torres, C.A. (Org.). The university, State and market: the 
political economy of globalization in the Americas. Stanford, Ca: Stanford University, 2006.

BOURDIEU, P. La noblesse d'Etat. Paris: Minuit, 1989.

BOURDIEU, P. Contrafogos: táticas para enfrentar a invasão neoliberal. Rio de Janeiro: Zahar, 1998.

BOURDIEU, P. Interventions: sciences sociales et action politique. Marseille: Agone, 2002.

BRASIL. Ministério da Educação. Projeto de Lei da Reforma da Educação Superior. Brasília, DF, 2006.

COBBAN, A. The medieval universities: their development and organization. London: Menthuen, 1975.

CROCHET, F. Governance in European universities. In: DuderstadT, J. (Org.). Reiventing the research university. Paris: Economica, 2004.

CUNHA, L.A. A universidade temporã: o ensino superior da colônia à era Vargas. Rio de Janeiro: Civilização Brasileira, 1980.

DUDERSTADT, J. A university for the $21^{\text {st }}$ millennium. Ann Arbor: University of Michigan, 2000.

DUDERSTADT, J. The future of the public university in America: beyond the crossroads. Baltimore: Johns Hopkins University, 2003.

GIDDENS, A. As conseqüências da modernidade. São Paulo: UNESP, 1991.

GIDDENS, A. A transformação da intimidade. São Paulo: UNESP, 1993.

GIDDENS, A. Mundo em descontrole: o que a globalização está fazendo de nós. Rio de Janeiro: Record, 2000.

GUADILLA, C.G. Educacion superior latinoamericana en los albores del tercer milênio. Caracas: Cendes, 2002.

HASKINS, C. The rise of universities. New York: Ithaca, 1977.

HEARN, J. Reseach on higher education in a mass an diversified system: the case of the United States. In: Altbach, P. (Org.). Higher

Educ. Soc., Campinas, vol. 27, n. 96 - Especial, p. 1001-1020, out. 2006 
Uma reforma necessária

education research at the turn of the new century: structures, issues, and trends. New York: Garland, 1997.

HARVEY, D. Condição pós-moderna. São Paulo: Loyola, 1989.

HOFTADTER, R. American higher education: a documentary history. Chicago: University of Chicago, 1971.

JACOBY, R. Os últimos intelectuais: a cultura americana na era da academia. São Paulo: EDUSP, 1990.

JACOBY, R. O fim da utopia: política e cultura numa era da apatia. Rio de Janeiro: Record, 2001.

KERR, C. The uses of universities. Cambridge, Mass.: Harvard University, 1982.

LUCAS, C. American higher education: a history. New York: St. Martin's, 1994.

LUCAS, C. Crisis in the academy: rethiking higher education in America. New York: St. Martin's, 1998.

NATRAJAN. R. The nature and scope of internationalization of higher education. In: POWAR, K.B. (Org.). Internationalization of Indian education. New Delhi: Association of Indian Universities, 2001.

NUNA, S. Internationalization of higher education: Australian experiences. In: POWAR, K.B. (Org.). Internationalization of Indian education. New Delhi: Association of Indian Universities, 2001.

ORGANISATION FOR ECONOMIC CO-OPERATION AND DEVELOPMENT (OCDE). Universities under scrutiny. Paris, 1987.

ORGANIZAÇÃO DAS NAÇŌES UNIDAS PARA A EDUCAÇÃO, CIENCIA E CULTURA (UNESCO). O ensino superior para o século XXI. Brasília, DF: UNESCO, 1999.

ORGANIZAÇÃO DAS NAÇÕES UNIDAS PARA A EDUCAÇÃO, CIÊNCIA E CULTURA. (UNESCO). A universidade na encruzilhada: por que e como reformar? Brasília, DF: UNESCO, 2004.

READINGS, B. The university in ruins. Massachusetts: Harvard University, 1996. 
RELATÓRIO da reforma do ensino superior. Paz \& Terra, Rio de Janeiro, n. 9, 1968.

RHODES.F. Governance of U.S. universities and colleges. In: DUDERSTADT, J. (Org.). Reinventing the research university. Paris: Economica, 2004.

RIBEIRO, R.J. A universidade e a vida atual. São Paulo: Campus, 2003.

RUCH, R. The rise of the for-profit university. Baltimore: John Hopkins University, 2001.

SLAUGTHER, S. Academic capitalism and the new economy: privatization as shifting the target of public subsidy in higher education, In: Torres, C.A. (Org.). The university, State and market: the political economy of globalization in the Americas. Stanford, Ca.: Stanford University, 2006.

SLAUGTHER, S. Academic capitalism and the new economy. Baltimore: John Hopkins University, 2004.

SCHWARTZMAN, S. A formação da comunidade cientifica no Brasil. Rio de Janeiro: FINEP, 1979.

SCHWARTZMAN, S. A redescoberta da cultura. São Paulo: EDUSP, 1997.

SOARES. S. (Org.). Educação superior no Brasil. Brasília, DF: CAPES/ UNESCO, 2002.

SOUZA SANTOS, B. Pela mão de Alice: o social e o político na pósmodernidade. São Paulo: Cortez, 1995.

SOUZA SANTOS, B. A universidade no século XXI. São Paulo: Cortez, 2004.

SCHUKOKSE. J. Academic exchange "global literacy" and U.s. higher education. In: POWAR, K.B. (Org.). Internationalization of Indian education. New Delhi: Association of Indian Universities, 2001.

SCOTT, P. The globalization of higher education. Lancaster: Open University, 1988.

SHAPIRO, H. A large sense of purpose: higher education and society. New Jersey: Princeton University, 2005. 
Uma reforma necessária

TORRES, C.A. Globalization and higher education in the Americas. In: Torres, C.A. (Org.). The university, State and market: the political economy of globalization in the Americas. Stanford, Ca: Stanford University Press, 2006.

TORRES, C.A. Globalization and the challenge to national universities in Argentina and Mexico. In: Torres, C.A. (Org.). The university, State and market: the political economy of globalization in the Americas. Stanford, Ca: Stanford University Press, 2006.

TRINDADE, H. (Org.). Os desafios da educação na América Latina. Petrópolis: Vozes, 2002.

TRUMBIC, S. Globalization and the market in higher education: quality, accreditation and qualifications. Paris: Economica, 2003.

TRIGUEIRO. M. Reforma universitária: mudanças no ensino superior brasileiro. Brasília, DF: Paralelo 15, 2004.

VERGER, J. Histoire des Universités en France. Toulouse: Privat, 1986.

VERGER, J. Homens e saber na Idade Média. Bauru: EDUSC, 1999.

VERGER, J. Cultura, ensino e sociedade no Ocidente. Bauru: EDUSC, 2001.

WEBER, L. Financing the research university: a European perspective. In: Duderstadt, J. (Org.). Reinventing the research university. London: Economica, 2004. 